\title{
Antarctic interglacial climate variability and implications for changes in ice sheet topography
}

\author{
Valérie Masson-Delmotte ${ }^{1}$, E. Capron ${ }^{2}$, H. Goosse ${ }^{3}$, K. Pol ${ }^{2}$, M. Siddall ${ }^{4}$, L. Sime ${ }^{2}$, S. Bradley and B. Stenni ${ }^{5}$ \\ 'Laboratoire des Sciences du Climat et de l'Environnement, CEA Saclay, Gif-sur-Yvette, France; valerie.masson@lsce.ipsl.fr \\ ${ }^{2}$ British Antarctic Survey, Cambridge, UK; ${ }^{3}$ Georges Lemaître Centre for Earth and Climate Research, Earth and Life Institute, Université catholique \\ de Louvain, Belgium; ${ }^{4}$ Department of Earth Sciences, University of Bristol, UK; ${ }^{5}$ Department of Geological, Environmental and Marine Sciences, \\ University of Trieste, Trieste, Italy
}

\section{New studies focusing on Antarctic climate variability during the current and earlier interglacial periods highlight the interplay between long-term climatic changes and climate variability in Antarctica, and enable the fingerprint of past changes in ice sheet topography to be investigated.}

$\mathrm{N}_{\mathrm{ftan}}$ w findings have arisen in the ramework of two ongoing European projects that aim at documenting and understanding past Antarctic climate variability. The ESF HOLOCLIP project focuses on Antarctic and marine records of the Holocene ( 15-0 ka BP), while the Past4Future project aims at, among other things, improved spatial and temporal coverage of the last interglacial (LIG; 129$118 \mathrm{ka}$ BP) in water stable isotopes from Antarctic ice cores.

By combining both data and model results obtained during two interglacial periods, characterized by different orbital configuration and over a large range of timescales (from multi-decadal to orbital), we show how these studies contribute to assessing the mechanisms responsible for Antarctic climate variability, and how they inform on the fingerprint of changes in ice sheet topography.

\section{The last millennium}

A good estimate of the magnitude and patterns of Antarctic temperature at a multi-decadal to centennial timescale during the last millennium is essential to understand the response of Antarctic climate to external forcings, and for assessing the ability of climate models to resolve the mechanisms at play (Goosse et al. 2012). Within HOLOCLIP, a composite of Antarctic temperature has been calculated by averaging temperature anomalies derived from seven ice core records (Fig. 1A). This simple method is supported by the coherency displayed between the average of the climate model results at the corresponding grid points, and the simulated average Antarctic temperature. Models and data rule out large $\left(>0.5^{\circ} \mathrm{C}\right)$ preindustrial temperature variations during the last millennium, and show $\sim 0.5^{\circ} \mathrm{C}$ warming since $1850 \mathrm{AD}$. Climate model simulations mainly attribute the multi-centennial cooling trend depicted from 1000 to $1850 \mathrm{AD}$ to volcanic forcing for annual mean temperature, while orbital forcing controls seasonal trends. Ongoing work aims at improving the documentation of Holocene climate and sea ice variability by combining ice core water stable isotope (Fig. 1B) and aerosol records with information from deepsea sediments and coastal records.

\section{Interglacial climate: mean state and variability}

Antarctic ice core records provide in sight to a diversity of interglacial periods, characterized by different durations, intensities, and trends (Jouzel et al. 2007; Uemura et al. 2012). Within the Past4Future project, new high-resolution water stable isotope measurements have been performed in order to assess past changes in high-resolution variability. In central Antarctica, deposition and post-deposition processes

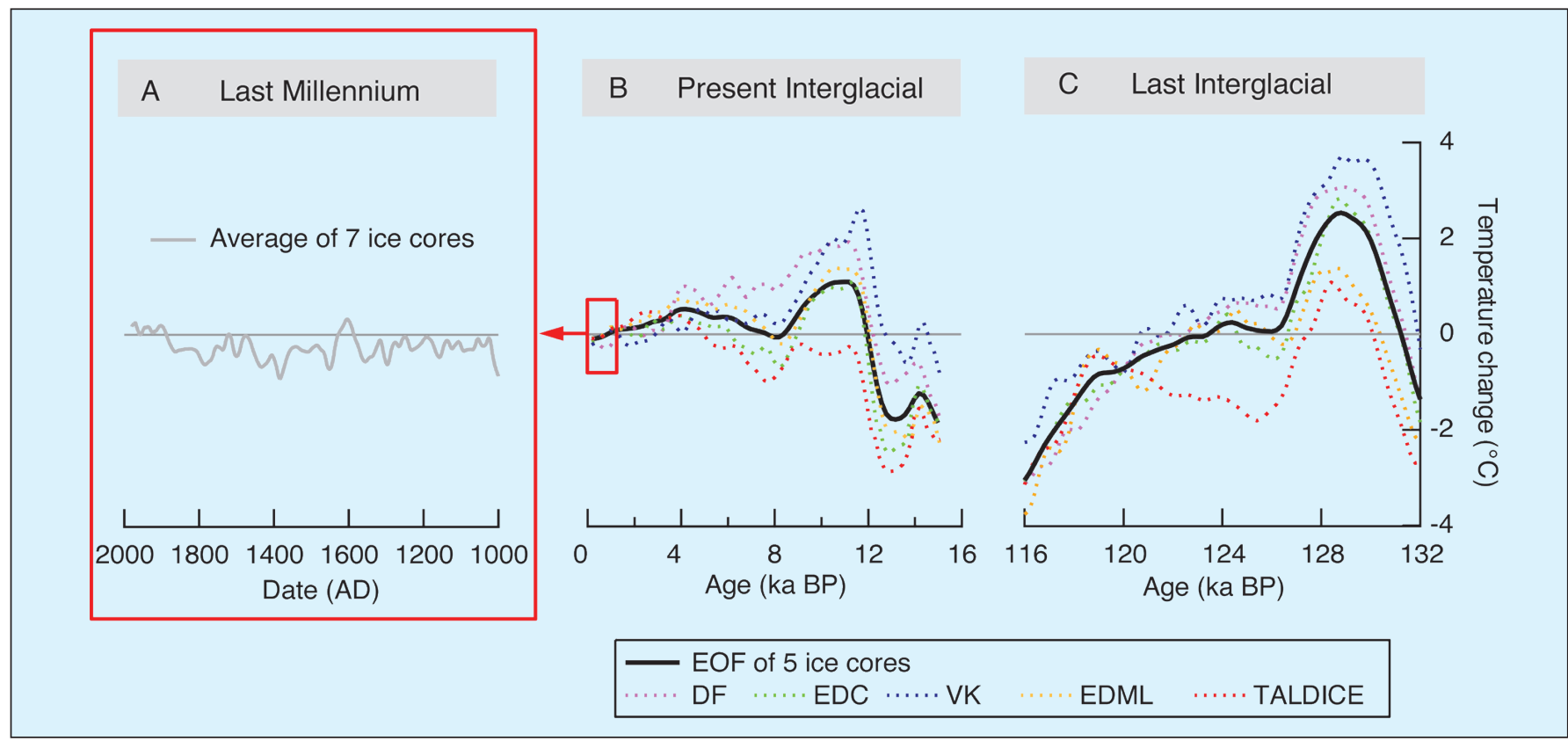

Figure 1: Antarctic records of the present interglacial and the last interglacial periods. This panel shows temperature estimates simply based on the spatial isotope-temperature gradient $\left(0.8 \% 0 \delta^{18} \mathrm{O}\right.$ per $\left.{ }^{\circ} \mathrm{C}\right)$ using $(\boldsymbol{A})$ a stack of seven ice cores for the last millennium and using individual ice cores (Vostok, VK; Dome F, DF; EPICA Dronning Maud Land, EDML; EPICA Dome C, EDC; Talos Dome, TALDICE) and the mean signal extracted using the first principal component (EOF1) for (B) the present interglacial and (C) the LIG. Modeling studies havesuggested that past changes in isotope-temperature relationships could lead to larger temperature changes than depicted here (e.g. Sime et al. 2009). 


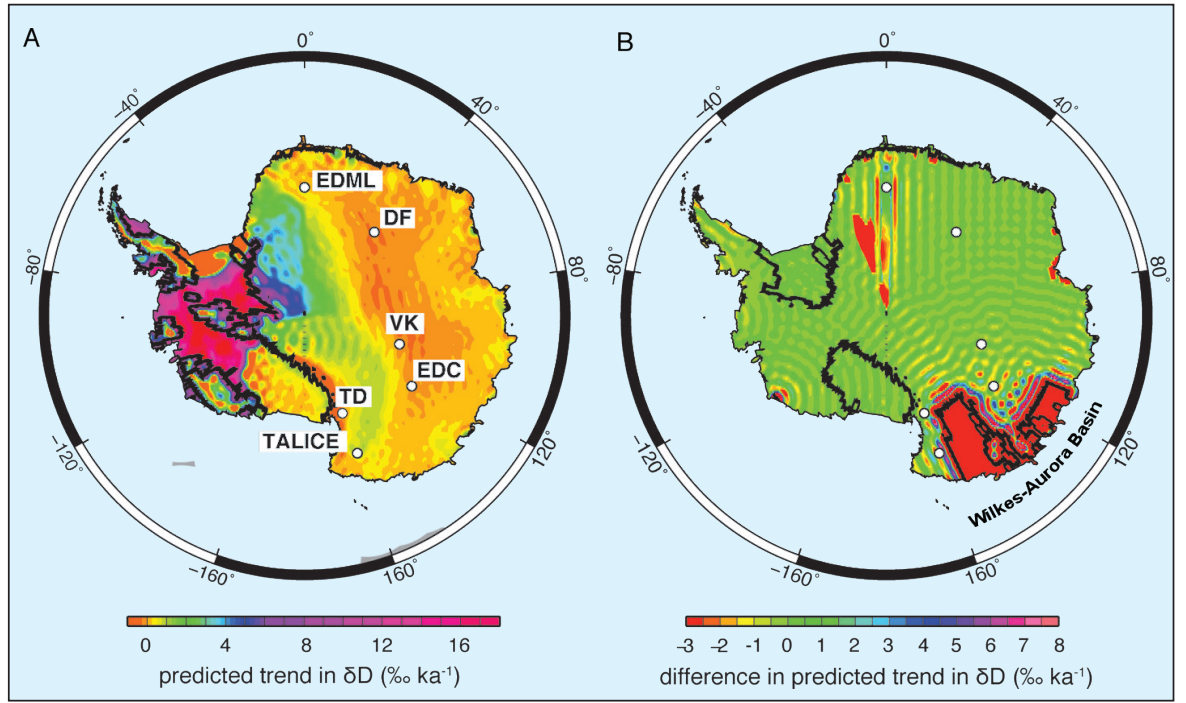

Figure 2: Simulated impacts of changes in Antarctic ice thickness and isostatic adjustment. Circles indicate ice core sites (Vostok, VK: Dome F, DF; EPICA Dronning Maud Land, EDML; EPICA Dome C, EDC; Talos Dome, TALDICE; Taylor Dome, TD) and the solid black lines highlight the location of the edge of each ice sheet model used. A) Predicted stable isotope trends (\%o kyr ${ }^{-1}$ ) driven by surface elevation changes only (not accounting for climatic impacts) resulting from a collapse of the WAIS (from 130 to $118 \mathrm{ka} \mathrm{BP}$ ). Note that the dark red and orange colors represent \%o kyr ${ }^{-1}$ values greater than the maximum (20) and minimum (-4) on the scale bar, respectively. B) Difference in the predicted stable isotope trends $\left(\%\right.$ kyr ${ }^{i}$ ) between a reference LIG Antarctic ice sheet model (Bradley et al. 2012) and a model (Bradley et al. 2013) where a significant retreat of marine-based ice in the Wilkes and Aurora basins of the East Antarctic Ice Sheet (from 126 to $118 \mathrm{ka} \mathrm{BP}$ ) has been simulated. Modified from Bradley et al. (2012) and Bradley et al. (2013).

such as precipitation intermittency and wind scouring limit the relevant temporal resolution to approximately 20 years. So far, a 45-year resolution has been achieved for Marine Isotopic Stage (MIS) 11 ( 400 ka, Pol et al. 2011) chosen as an exceptionally long interglacial, and a 20-year resolution for the LIG (Pol et al. unpublished data), chosen as an exceptionally warm period.

In Antarctica, MIS 11 is marked by a multi-millennial-long increasing trend, which then decreases. High-resolution deuterium measurements have revealed increased sub-millennial climatic variability in the decreasing temperature phase. During the LIG (Fig. 1C), Antarctic temperature exhibits an early maximum, which corresponds to a bipolar seesaw with respect to Northern Hemisphere climate (Masson-Delmotte et al. 2010). It is followed by a multi-millennial scale plateau, then by a cooling into the glacial inception, punctuated by the onset of glacial millennial climatic variability, established at around 110 ka BP (Capron et al. 2012). Our unpublished high-resolution deuterium data point to minimum variance during the LIG "plateau", above Holocene levels and an increasing sub-millennial climatic variability at the end of the interglacial phase, as observed for MIS 11.

\section{Tracking changes in the Antarctic ice sheet topography}

Further investigation of the Antarctic climate during the LIG was achieved by comparing the records available from six East Antarctic ice cores with their Holocene data. In addition to the common features previously described and well captured in the EPICA Dome $C$ ice core, the same regional differences are depicted during the current and LIG periods. Some earlier studies have shown to precipitation intermittency (e.g. Sime et al. 2009). However, an alternative interpretation lies in different elevation histories due to the interplay between local ice thickness and isostatic adjustment.

The cause for peak Antarctic warmth during the LIG remains disputed. Astronomical forcing alone does not allow climate models to produce warmer than present day Antarctic temperatures. Therefore, other hypotheses such as the bipolar seesaw linked with large-scale ocean circulation perhaps along with the climate impacts of a collapse of the West Antarctic ice sheet (Holden et al. 2008), could explain the early Antarctic optimum. Recent studies have stressed that the Greenland ice sheet may have made only a limited contribution (about $+2 \mathrm{~m}$ of equivalent sea level) to the LIG highstand, pointing to a significant contribution of the West and/or East Antarctic ice sheets to the estimated 6-to-10-m high stand (NEEM community members 2013; Dahl-Jensen et al. this issue).

At the intersection of Past4Future Work Packages focused on interglacial that these differences can be attributed climate variability and ice sheet dynamics (e.g. Siddall et al. this issue), different Past4Future partners have started to explore if a fingerprint of past changes in the Antarctic ice loading could be detected as an elevation-driven temperature trend preserved in East Antarctic ice cores. A "treasure map" was produced, identifying potential drilling sites where a clear fingerprint of a West Antarctic ice sheet collapse could be identified (Bradley et al. 2012). These sites, unfortunately, do not coincide with existing ice core records (Fig. 2A). The same approach proved more successful for the Wilkes-Aurora Basin sector of the East Antarctic ice sheet, and preliminary results (Bradley et al. 2013), assuming a homogeneous climate history, suggest that differences between the coastal TALDICE and central EPICA Dome C water isotopic records may provide information on changes in East Antarctic ice sheet topography (Fig. 2B). This brief overview of recent studies, dedicated to the variability of Antarctic climate during the current and earlier interglacial periods, shows new findings regarding both the interplay between mean climate state and polar climate variability at shorter time scales and new implications for climate - ice sheet evolution.

\section{Outlook}

New information from Antarctic ice cores is needed to further assess the spatial coherency of interglacial climate variability and the relationships between climate and the water cycle, including all water stable isotopes. The use of ice core information alongside ice sheet and climate modeling (including water isotopes) has the potential to test model capabilities and help us reduce uncertainty about the response of the Antarctic ice sheet to warmer than present climate conditions.

\section{Selected references}

Full reference list online under:

http://www.pages-igbp.org/products/newsletters/ref2013_1.pdf

Bradley SL et al. (2012) Global and Planetary Change 88-89: 64-75 Bradley SL et al. (2013) Global and Planetary Change 100: 278-290 Capron E et al. (2012) Geophysical Research Letters 39(15), doi: 10.1029/2012GL052656

Goosse H et al. (2012) Quaternary Science Reviews 55: 75-90 Pol K et al. (2011) Climate of the Past 7(2): 437-450 